\title{
Mucin-Producing Neoplasms of the Pancreas: An Analysis of Distinguishing Clinical and Epidemiologic Characteristics
}

\section{Citation}

Crippa, Stefano, Carlos Fernández-del Castillo, Roberto Salvia, Dianne Finkelstein, Claudio Bassi, Ismael Domínguez, Alona Muzikansky, et al. 2010. Mucin-producing neoplasms of the pancreas: An analysis of distinguishing clinical and epidemiologic characteristics. Clinical Gastroenterology and Hepatology 8(2): 213-219. doi:10.1016/j.cgh.2009.10.001

\section{Published Version}

doi:10.1016/j.cgh.2009.10.001

\section{Permanent link}

http://nrs.harvard.edu/urn-3:HUL.InstRepos:32541453

\section{Terms of Use}

This article was downloaded from Harvard University's DASH repository, and is made available under the terms and conditions applicable to Other Posted Material, as set forth at http:// nrs.harvard.edu/urn-3:HUL.InstRepos:dash.current.terms-of-use\#LAA

\section{Share Your Story}

The Harvard community has made this article openly available.

Please share how this access benefits you. Submit a story.

Accessibility 


\title{
Mucin-Producing Neoplasms of the Pancreas: An Analysis of Distinguishing Clinical and Epidemiologic Characteristics
}

\author{
STEFANO CRIPPA ${ }^{*}$, CARLOS FERNÁNDEZ-DEL CASTILLO $¥$, ROBERTO SALVIA ${ }^{*}$, DIANNE \\ FINKELSTEIN ${ }^{\S}$, CLAUDIO BASSI ${ }^{\star}$, ISMAEL DOMÍNGUEZ ${ }^{\ddagger}$, ALONA MUZIKANSKY $§$, SARAH \\ P. THAYER ${ }^{\ddagger}$, MASSIMO FALCONI ${ }^{\star}$, MARI MINO-KENUDSON $\|$, PAOLA CAPELLIף, \\ GREGORY Y. LAUWERS $\|$, STEFANO PARTELLI ${ }^{*}$, PAOLO PEDERZOLI ${ }^{*}$, and ANDREW L. \\ WARSHAW $\ddagger$ \\ ‡ Department of Surgery, Massachusetts General Hospital, Harvard Medical School, Boston, \\ Massachusetts \\ I| Department of Pathology, Massachusetts General Hospital, Harvard Medical School, Boston, \\ Massachusetts \\ $\S$ Department of Biostatistics, Massachusetts General Hospital, Harvard Medical School, Boston, \\ Massachusetts \\ " Department of Surgery, Policlinico "GB Rossi", University of Verona, Verona, Italy \\ I Department of Pathology, Policlinico "GB Rossi”, University of Verona, Verona, Italy
}

\section{Abstract}

BACKGROUND \& AIMS-Mucin-producing neoplasms (MPNs) of the pancreas include mucinous cystic neoplasms (MCNs) and main-duct, branch-duct, and combined intraductal papillary mucinous neoplasms (IPMNs). MCNs and branch-duct IPMNs are frequently confused; it is unclear whether main-duct, combined, and branch-duct IPMNs are a different spectrum of the same disease. We evaluated their clinical and epidemiologic characteristics.

\begin{abstract}
METHODS-Patients who underwent resection for histologically confirmed MPNs were identified $(\mathrm{N}=557)$; specimens were reviewed and eventually re-classified.
\end{abstract}

RESULTS-One hundred sixty-eight patients (30\%) had MCNs, 159 (28.5\%) had branch-duct IPMNs, 149 (27\%) had combined IPMNs, and 81 (14.5\%) had main-duct IPMNs. Patients with MCNs were significantly younger and almost exclusively women; $44 \%$ of patients with main-duct or combined IPMNs and 57\% of those with branch-duct IPMNs were women. MCNs were single lesions located in the distal pancreas (95\%); $11 \%$ were invasive. IPMNs were more frequently found in the proximal pancreas; invasive cancer was found in $11 \%, 42 \%$, and $48 \%$ of branch-duct, combined, and main-duct IPMNs, respectively $(P=.001)$. Patients with invasive MCN and those with combined and main-duct IPMNs were older than those with noninvasive tumors. The 5-year disease-specific survival rate approached $100 \%$ for patients with noninvasive MPNs. The rates for

\footnotetext{
(C) 2010 by the AGA Institute

Reprint requests: Address requests for reprints to: Carlos Fernández-del Castillo, MD, Department of Surgery, Massachusetts General Hospital, Wang Ambulatory Care Center 460, 15 Parkman Street, Boston, Massachusetts 02114. cfernandez@ partners.org; fax: (617) 724-3383.

Drs Pederzoli and Warshaw contributed equally to this work.

Conflicts of interest

The authors disclose no conflicts.

Supplementary Data

Note: to access the supplementary materials accompanying this article, visit the online version of Clinical Gastroenterology and Hepatology at www.cghjournal.org.
} 
those with invasive cancer were 58\%,56\%, 51\%, and $64 \%$ for invasive MCNs, branch-duct IPMNs, main-duct IPMNs, and combined IPMNs, respectively.

CONCLUSIONS-MPNs comprise 3 different neoplasms: MCNs, branch-duct IPMNs, and main-duct IPMNs, including the combined type. These tumors have specific clinical, epidemiologic, and morphologic features that allow a reasonable degree of accuracy in preoperative diagnosis.

Twenty-five years ago, Ohashi et $\mathrm{al}^{1}$ described 4 cases of an unusual form of pancreatic adenocarcinoma characterized by overproduction of mucus and diffuse distention of the pancreatic ductal system. A decade later, small case reports referred to this condition as "mucinous ductal ectasia," pancreas by the World Health Organization labeled these tumors as intraductal papillary mucinous neoplasms (IPMNs), ${ }^{5}$ which could in different cases involve the main pancreatic duct (MPD) alone, the main duct and the branch ducts, or exclusively the side branches of the pancreas. ${ }^{6}$ During the last decade, IPMNs have become commonly diagnosed, often in patients with mild or no symptoms. ${ }^{7,8}$ Increasing evidence indicates that branch-duct IPMN is much less likely to harbor cancer than IPMN affecting the MPD, ${ }^{9-11}$ and in fact, recent guidelines put forward by the International Association of Pancreatology recommend observation alone for asymptomatic patients with branch-duct IPMNs that measure less than $3 \mathrm{~cm}$ in diameter and have no nodules. ${ }^{11}$ For many years another mucin-producing lesion of the pancreas, the mucinous cystic neoplasm (MCN), was confused or misdiagnosed with IPMN. Whereas IPMNs arise in the ductal system, MCNs do not, and unlike IPMNs, they characteristically contain an ovarian-like stroma. ${ }^{11-13}$ Inasmuch as the distinction between main-duct, branch-duct, and combined IPMNs is relatively recent and because the distinction between small MCNs and small branch-duct IPMNs can be quite difficult without full histologic analysis, accurate epidemiologic data distinguishing among the different mucin-producing neoplasms (MPNs) of the pancreas have been unreliable. ${ }^{11,12,14,15}$ It is still unclear whether main-duct and branch-duct IPMNs are different points on a spectrum or altogether different diseases, and where combined IPMNs fit.

The purpose of this study was to re-examine and compare the characteristics of a large cohort of patients with pathologically confirmed MPNs of the pancreas. Although we have previously reported the treatment of many of these patients, ${ }^{13,14,16}$ this new analysis brings together this group of neoplasms to highlight their differences and similarities.

\section{Methods}

All patients who underwent pancreatic resection between January 1988 and December 2006 with a final histologic diagnosis of pancreatic MPNs were identified from prospective databases maintained at the Departments of Surgery of Massachusetts General Hospital, Boston, MA and of the University of Verona, Verona, Italy. Approval for this study was obtained from the Institutional Review Board at each institution.

Because the pathologic criteria for the classification of pancreatic MPNs have changed over time, all surgical specimens were re-reviewed by senior pancreatic pathologists and classified as MCNs, main-duct, branch-duct, and combined-IPMNs. The number of histologic slides analyzed for all the specimens, including both MCNs and IPMNs, ranged from 3-94. Indeterminate mucinous cystic lesions were excluded from this study. Detailed diagnostic criteria ${ }^{5,6,11}$ are reported as supplementary material (Supplementary Document 1). Figure 1 and Supplementary Figures 1 and 2 show examples of radiologic, endoscopic, and pathologic images of different MPNs. 


\section{Study Population}

During the study period 592 patients were found to have pancreatic MPNs. Thirty-five (6\%) had an indeterminate mucinous cystic lesion and were excluded from this analysis, leaving 557 patients to constitute the study population. Of these, 168 (30\%) had MCNs, 159 (28.5\%) had branch-duct IPMNs, 149 (27\%) had combined IPMNs, and 81 (14.5\%) had main-duct IPMNs.

Information including demographics, clinical history, family history of pancreatic cancer, history of other malignant neoplasms, pathologic findings, and long-term follow-up was obtained from our prospective databases. For the purpose of survival analysis, patients with adenoma, borderline neoplasm, and carcinoma in situ were grouped as non-invasive and were compared with patients with invasive carcinoma arising from either MCNs or IPMNs. Detailed information regarding clinical history, symptoms, and timing of follow-up are reported as supplementary material (Supplementary Document 2).

\section{Statistical Analysis}

The goal of the present analysis was to elucidate (1) whether branch-duct, main-duct, and combined IPMNs represent distinct diseases and (2) the similarities and differences between MCNs and IPMNs, because these 2 entities have been largely confused. ${ }^{11-15}$

Results are presented as frequencies and percentages for categorical variables and as median (range) for continous variables. Categorical variables were compared by using a $\chi^{2}$ test and Fisher exact test as appropriate. When comparing 2 groups, normally distributed continuous variables were analyzed by using a 2-sample Student $t$ test, whereas the Mann-Whitney $U$ test was used for non-normally distributed variables. One-way analysis of variance with post hoc analysis was performed for multiple comparisons with normal distribution, and the probability was adjusted by Tukey's correction.

Multivariate logistic models were fit by using stepwise regression. A $P$ value was considered statistically significant if the two-sided test $P$ value was $<.05$. Survival analysis was done by using the Kaplan-Meier function, comparing patients with different histotypes with the log-rank test.

\section{Results}

\section{Main-Duct, Combined, and Branch-Duct Intraductal Papillary Mucinous Neoplasms}

Table 1 shows the characteristics of patients with main-duct, combined, and branch-duct IPMNs. Patients were elderly, with no age differences among the 3 groups. Main-duct and combined IPMNs occured more frequently in men (55.5\% of main-duct IPMNs and $56 \%$ of combined type), whereas branch-duct IPMNs occurred more frequently in women (57\%) (main-duct versus branch-duct, $P=.04$; combined versus branch-duct, $P=.01$ ).

Approximately $20 \%$ of patients with IPMNs, regardless of type, had a clinical history of other malignant neoplasms (Supplementary Table 1). All IPMN subtypes were more frequently located in the proximal pancreas. Diffuse neoplasms were found in $4 \%$ of mainduct IPMNs, $10 \%$ of combined type, and 37\% of branch-duct IPMNs. Main-duct and combined type neoplasms extended continually along the MPD, whereas branch-duct IPMNs presented discontinually as multiple distinct lesions.

Incidental diagnosis was significantly more common in branch-duct IPMNs (34.5\%) compared with main-duct (13.5\%) and combined (19\%) types. Abdominal pain or discomfort was a common symptom at diagnosis in all IPMN types; however, objective 
symptoms (ie, jaundice) were significantly more frequent in main-duct and combined IPMNs.

Adenoma was the most common histotype in branch-duct IPMNs (44\%). The prevalence of adenomas in main-duct and combined IPMNs was significantly lower (11\% and $8 \%$, respectively). Conversely, invasive cancer was significantly higher in main-duct (48\%) and combined IPMNs (42\%) compared with branch-duct lesions (11\%).

In patients with IPMNs containing invasive cancers, the frequency of lymph node metastases was 33\% in main-duct IPMNs, $48.5 \%$ in combined, and $23.5 \%$ in branch-duct IPMNs. Moreover, although the age of patients with invasive versus noninvasive branchduct IPMNs was similar (median, 66 versus 68 years; $P=.2$ ), patients with invasive mainduct IPMNs were significantly older than those with noninvasive ones (median, 69 versus 64.5 years; $P=.04$ ). Patients with combined IPMNs with invasive cancer were older than their noninvasive counterparts (median, 67.5 versus 64 years), but this difference did not achieve statistical significance $(P=.1)$.

Because the epidemiologic and clinicopathologic characteristics of main-duct and combined IPMNs were very similar, main-duct and combined IPMNs were grouped together and compared with branch-duct IPMNs in multivariate analysis. The logistic regression model (Table 2) showed that gender, weight loss, and the presence of an invasive tumor remained significant in differentiating these IPMN subtypes.

\section{Mucinous Cystic Neoplasms Versus Branch-Duct Intraductal Papillary Mucinous Neoplasms}

The clinicopathologic characteristics of these 2 groups are shown in Table 3. Patients with MCNs were significantly younger than those with branch-duct IPMNs (median, 44.5 versus 66 years; $P=.0001$ ), and they were almost exclusively women (95\% versus $57 \% ; P=.0001$ ). The frequency of other malignant neoplasms (Supplementary Table 1) was higher in branchduct IPMNs (20\% versus 9\%; $P=.006)$.

Practically all MCNs were located in the distal pancreas (97\%), whereas most branch-duct IPMNs (52\%) were in the proximal pancreas; $37 \%$ of branch-duct IPMNs were multifocal, but all MCNs were single cystic lesions. Overall, $72.5 \%$ of MCN patients and $65.5 \%$ of those with branch-duct IPMNs were symptomatic, and specific symptoms were significantly more frequent in branch-duct IPMNs.

The prevalence of invasive carcinoma was the same (11\%) in the 2 groups. MCNs showed a higher frequency of adenoma (73\% versus $44 \%)$ and a lower frequency of borderline neoplasms (10\% versus $34 \%$ ) and carcinoma in situ (6\% versus $11 \%)$. Strikingly, no lymph node metastases were found associated with invasive MCNs, whereas $23.5 \%$ of patients with invasive branch-duct IPMNs did have metastatic nodes. Among all the factors found to be significantly different between MCNs and branch-duct IPMNs, age, gender, presence of acute pancreatitis, and distal pancreas as tumor site remained significant in the multivariate logistic model (Table 4).

\section{Tumor Recurrence and Survival}

Follow-up was available in $97 \%$ of the patients. The median follow-up for the entire cohort was 50 months (range, 2-233 months) and 61 months (range, 8-233 months) for living patients. The 5-year survival for all patients with MCNs, branch-duct IPMNs, main-duct IPMNs, and combined IPMNs was 94\%, 91\%, 65\%, and 77\%, respectively (Supplementary Figure 3). The 5-year disease-specific survival for patients with noninvasive branch-duct IPMNs was $100 \%$, and it was $56 \%$ for those with invasive cancer (Figure $2 a$ ). Thirteen 
patients (8\%) with branch-duct IPMNs had a recurrence. Of these, 6 patients with an adenoma developed a new (metachronous) branch-duct IPMN that was asymptomatic and small in size $(<30 \mathrm{~mm})$; these patients are being managed conservatively. The remaining 7 patients originally had an invasive carcinoma, which recurred after a mean of 28 months (range, 6-72 months) with distant metastases (liver and lungs), accounting for a recurrence rate of $41 \%$.

The 5-year disease-specific survival was $95 \%$ for patients with noninvasive main-duct IPMNs and 51\% for those with invasive carcinoma (Figure 2b). Overall, 19 patients (23.5\%) developed a recurrence. One patient with carcinoma in situ who had total pancreatectomy because of an involvement of the entire gland developed histologically confirmed, intraperitoneal carcinomatosis with pseuodomyxoma peritonei 38 months after initial surgery. No invasive cancer was found in the resected total pancreatectomy specimen, and the patient subsequently died of metastatic disease. Seventeen of the 39 patients $(43.5 \%)$ with invasive carcinoma developed local recurrence $(n=3)$ or liver metastases $(n=14)$ after a mean of 20.6 months (range, 4-50 months). In combined IPMNs, the 5-year diseasespecific survival was $100 \%$ and $64 \%$ for noninvasive and invasive neoplasms, respectively (Figure $2 c$ ). Twenty-seven patients (18\%) developed tumor recurrence. Of these, 25 patients originally had invasive carcinoma, accounting for a recurrence rate of $40 \%$ in this subgroup, and developed tumor recurrence after a mean of 18.5 months (range, 4-67 months). Twentytwo patients had metastatic disease, whereas the remaining 2 had only local recurrence.

The 5-year disease-specific survival for MCNs was $100 \%$ and $58 \%$ for patients with noninvasive and invasive tumors, respectively (Figure $2 d$ ). Patients with noninvasive neoplasms had no recurrences. Seven patients, comprising 37\% of invasive carcinomas, developed tumor recurrence in the peritoneum or liver after a mean of 32.5 months (range, 4-99 months).

\section{Discussion}

The apparent incidence of MPNs of the pancreas, and particularly of IPMNs, has increased markedly during the past 15 years; these now represent one of the most common indications for pancreatic resection at high-volume centers. ${ }^{14-17}$ The higher numbers of reported cases might be due to improved imaging techniques, greater awareness of this pathology by the gastroenterological community, and increased incidental diagnosis among asymptomatic individuals.

It is only in recent years that a clear distinction between MCNs and IPMNs and between branch-duct and main-duct IPMNs has emerged. ${ }^{13-18}$ Growing knowledge of their biologic behavior indicates that clear identification and distinction of MCNs and main-duct and branch-duct IPMNs are not only of taxonomic significance but have a practical impact on patient management. For example, branch-duct IPMNs appear to carry a much lower risk of malignant degeneration compared with main-duct IPMNs, and nonsurgical management with surveillance is feasible for many of these lesions, thereby avoiding "prophylactic" pancreatectomy with its associated risks. ${ }^{8,11,16,19-24}$ Nonetheless, in the past, a strict distinction was not made between the variants of IPMNs and MCNs.

As yet there has been no consensus as to whether main-duct and branch-duct IPMNs are 2 different neoplasms or a spectrum of the same condition, and whether combined IPMNs are a progression of main-duct or branch-duct type or a distinct disease as well. ${ }^{11,14,17}$ The latter question is of strategic importance because if combined IPMNs turn out to be a progression from branch-duct IPMNs, this would mandate a closer long-term surveillance of branch-duct IPMNs than is currently advised. 
To provide clear-cut, reproducible distinctions between main-duct, branch-duct, and combined IPMNs and MCNs, we applied strict histopathologic criteria in our reviewing of 592 cases of MPNs of the pancreas. We excluded 35 mucinous lesions of indeterminate classification comprising $6 \%$ of the series.

Our study showed that branch-duct IPMNs have a specific profile, likely representing an entity distinct from other IPMNs, and that combined IPMNs show close overlapping similarities with main-duct IPMNs in regard to clinicopathologic and epidemiologic characteristics. For example, we found that main-duct and combined IPMNs have the same sex ratio (female, $44 \%$; male, 56\%), opposite to that of branch-duct type (female, 57\%; male, $43 \%$ ). Although the median age at presentation was similar in the 3 groups, patients affected by main-duct and combined IPMNs with invasive cancer were significantly older than those with noninvasive neoplasms. This age difference suggests progression from adenoma to invasive carcinoma, a finding that was not present in branch-duct IPMNs. Furthermore, branch-duct IPMNs were more likely to be asymptomatic, whereas the majority of patients with main-duct and combined IPMNs were symptomatic. Finally, most patients with branch-duct IPMNs had an adenoma (44\%), whereas the prevalence of cancer was $22 \%$ (invasive cancer, $11 \%$ ). In contrast, main-duct and combined IPMNs contained malignant elements in $68 \%$ and $62 \%$, respectively, with invasive cancer present in $48 \%$ and $42 \%$. Considering these findings, we conclude that combined IPMNs likely represent an extension of main-duct IPMNs to the branch ducts of the pancreas. The similar age differential between noninvasive and invasive tumors ${ }^{14,18}$ and the greater frequency of malignancy in both main-duct and combined IPMNs suggest that these 2 IPMN subgroups share not only common morphology but also an aggressive biology characterized by progression to invasive cancer.

No significant differences were found among the 3 groups with respect to disease-specific survival. The disease-specific survival rates found for all these types of IPMNs with invasive cancer appear to be higher than those seen in ductal adenocarcinoma of the pancreas and are consistent with other previously reported series. ${ }^{14,16,18}$ However, Schnelldorfer et $\mathrm{al}^{25}$ reported no differences in overall survival when comparing 63 patients with invasive IPMNs and 63 matched patients (by disease stage) with ductal adenocarcinoma (5-year survival, $31 \%$ versus $24 \% ; P=.26$ ). A disease-specific survival analysis was not performed in this study. Larger studies with longer follow-up and careful patient stratification by disease stage and histopathologic prognostic criteria are needed to confirm these findings.

A surprising observation was the peritoneal recurrence 38 months from initial surgery in a patient with main-duct IPMN with in situ carcinoma who underwent total pancreatectomy. In retrospect, the specimen was divided during resection, thereby allowing mucin to spill from the resected duct, and we presume that tumor cells were seeded at this time. This experience, albeit rare, raises a concern about allowing egress of duct contents that might harbor tumor cells. Local recurrence or metachronous lesions in the pancreatic remnant were detected in patients with both invasive and noninvasive IPMNs, hypothesizing a "field defect" in the entire pancreas that could mandate lifetime surveillance. ${ }^{11,26,27}$

A second end point of the study was to compare MCNs and branch-duct IPMNs because MCNs and branch-duct IPMNs can be potentially confused, at least in the preoperative setting. ${ }^{11-13}$ Our data suggest that when strict histologic criteria are applied, in particular the presence of ovarian-like stroma, these neoplasms have very distinct clinicopathologic and epidemiologic features. In multivariate analysis, age, gender, site, and the presence of acute pancreatitis were independent predictors useful to distinguish MCNs and branch-duct IPMNs. Typically, MCNs present as a large cyst located in the distal pancreas of a middle- 
aged woman and have no connection with the ductal system. However, the differential diagnosis of small cysts located in the distal pancreas might be difficult. Modern imaging techniques, particularly magnetic resonance with cholangiopancreatography and endoscopic ultrasound, might demonstrate pancreatic duct branches emanating from the cyst lesion, thereby defining it as an IPMN. ${ }^{17,28}$ Multifocal cysts also indicate IPMNs, inasmuch as MCNs are always single.

The distinction among main-duct, branch-duct, and combined IPMNs and MCNs has major implications in clinical practice. Recent guidelines suggest that nonoperative management is safe for patients with asymptomatic branch-duct IPMNs $<3 \mathrm{~cm}$ in size without nodules, ${ }^{11}$ whereas there is a general consensus that the risk of malignancy in any IPMN involving the MPD should be viewed with concerns (and resected). ${ }^{14,17,18}$ Our study indicated that the risk of cancer in MCNs (11\% invasive and 6\% in situ) is relatively low and potentially could allow for nonoperative management in the majority-those that are asymptomatic, less than $4 \mathrm{~cm}$ in diameter, and without solid components. However, because most of these are diagnosed in young women with long life expectancy, the cost-effectiveness and safety of this approach should be carefully considered and balanced with the potential costs of postoperative pancreatic endocrine insufficiency. ${ }^{13,15,16}$

In summary, the results of this study showed that MCNs of the pancreas comprise 3 (not 4) different neoplasms: MCNs, branch-duct IPMNs, and main-duct IPMNs including the combined type. These tumors have specific clinical and morphologic features that allow a reasonable degree of accuracy in preoperative differential diagnosis and thereby influence the strategy for clinical management.

\section{Supplementary Material}

Refer to Web version on PubMed Central for supplementary material.

\section{Acknowledgments}

Funding

This study was supported by the International Hepato-Pancreato-Biliary Association (Warren Fellowship Award to S.C.), Fundacion Harvard en Mexico (to I.D.), Fondazione Italiana Malattie Pancreas.

\section{Abbreviations used in this paper}

$\begin{array}{ll}\text { IPMN } & \text { intraductal papillary mucinous neoplasm } \\ \text { MCN } & \text { mucinous cystic neoplasm } \\ \text { MPD } & \text { main pancreatic duct } \\ \text { MPN } & \text { mucin-producing neoplasm }\end{array}$

\section{References}

1. Ohashi K, Murakami Y, Murayama M, et al. Four cases of mucus secreting pancreatic cancer. Prog Dig Endoscopy. 1982; 20:348-351.

2. Warshaw AL, Compton CC, Lewandrowski K, et al. Cystic tumors of the pancreas: new clinical, radiologic, and pathologic observations in 67 patients. Ann Surg. 1990; 212:432-443. [PubMed: 2171441]

3. Yamaguchi K, Tanaka M. Mucin-hypersecreting tumor of the pancreas with mucin extrusion through an enlarged papilla. Am J Gastroenterol. 1991; 86:835-839. [PubMed: 2058624] 
4. Kawarada Y, Yano T, Yamamoto T, et al. Intraductal mucin-producing tumors of the pancreas. Am J Gastroenterol. 1992; 87:634-638. [PubMed: 1317671]

5. Kloppel, G.; Solcia, E.; Longnecker, DS., et al. World Health Organization international histological typing of tumors of the exocrine pancreas. Berlin: Springer-Verlag; 1996. p. 1-61.

6. Longnecker, DS.; Hruban, RH.; Kloppel, G. Intraductal papillary-mucinous neoplasms of the pancreas. In: Hamilton, SR.; Aaltonen, LA., editors. World Health Organization classification of tumors: pathology and genetics of tumors of the digestive system. Lyon: IARC Press; 2000. p. 237-241.

7. Fernandez-del Castillo C, Targarona J, Thayer SP, et al. Incidental pancreatic cysts: clinicopathologic characteristics and comparison with symptomatic patients. Arch Surg. 2003; 138:427-433. [PubMed: 12686529]

8. Salvia R, Crippa S, Falconi M, et al. Branch-duct intraductal papillary mucinous neoplasms of the pancreas: to operate or not to operate? Gut. 2007; 56:1086-1090. [PubMed: 17127707]

9. Kobari M, Egawa S, Shibuya K, et al. Intraductal papillary mucinous tumors of the pancreas comprise 2 clinical subtypes: differences in clinical characteristics and surgical management. Arch Surg. 1999; 134:1131-1136. [PubMed: 10522860]

10. Terris B, Ponsot P, Paye F, et al. Intraductal papillary mucinous tumors of the pancreas confined to secondary ducts show less aggressive pathologic features as compared with those involving the main pancreatic duct. Am J Surg Pathol. 2000; 24:1372-1377. [PubMed: 11023098]

11. Tanaka M, Chari S, Adsay V, et al. International Association of Pancreatology: international consensus guidelines for management of intraductal papillary mucinous neoplasms and mucinous cystic neoplasms of the pancreas. Pancreatology. 2006; 6:17-32. [PubMed: 16327281]

12. Reddy RP, Smyrk TC, Zapiach M, et al. Pancreatic mucinous cystic neoplasm defined by ovarian stroma: demographics, clinical features, and prevalence of cancer. Clin Gastroenterol Hepatol. 2004; 2:1026-1031. [PubMed: 15551256]

13. Crippa S, Salvia R, Warshaw AL, et al. Mucinous cystic neoplasm is not an aggressive entity: lessons from 163 resected patients. Ann Surg. 2008; 247:571-579. [PubMed: 18362619]

14. Salvia R, Fernandez-del Castillo C, Bassi C, et al. Main-duct intraductal papillary mucinous neoplasms of the pancreas: clinical predictors of malignancy and long-term survival following resection. Ann Surg. 2004; 239:678-685. [PubMed: 15082972]

15. Sonnenday CJ, Simeone DM. "Criminal" profiling of the pancreas: when is aggressive therapy indicated for a non-aggressive entity? Ann Surg. 2008; 247:580-582. [PubMed: 18362620]

16. Rodriguez JR, Salvia R, Crippa S, et al. Branch-duct intraductal papillary mucinous neoplasms: observations in 145 patients who underwent resection. Gastroenterology. 2007; 133:72-79. [PubMed: 17631133]

17. Crippa S, Fernandez-del Castillo C. Management of intraductal papillary mucinous neoplasms of the pancreas. Curr Gastroenterol Rep. 2008; 10:136-143. [PubMed: 18462599]

18. Sohn TA, Yeo CJ, Cameron JL, et al. Intraductal papillary mucinous neoplasms of the pancreas: an updated experience. Ann Surg. 2004; 239:788-797. [PubMed: 15166958]

19. Tanno S, Nakano Y, Nishikawa T, et al. Natural history of branch duct intraductal papillarymucinous neoplasms of the pancreas without mural nodules: long-term follow-up results. Gut. 2008; 57:339-343. [PubMed: 17660227]

20. Levy P, Jouannaud V, O'Toole D, et al. Natural history of intraductal papillary mucinous tumors of the pancreas: actuarial risk of malignancy. Clin Gastroenterol Hepatol. 2006; 4:460-468. [PubMed: 16616351]

21. Palaez-Luna M, Chari ST, Smyrk TC, et al. Do consensus indications for resection in branch-duct intraductal papillary mucinous neoplasm predict malignancy? a study of 147 patients. Am J Gastroenterol. 2007; 102:1759-1764. [PubMed: 17686073]

22. Rautou PE, Levy P, Vuillierme MP, et al. Morphologic changes in branch duct intraductal papillary mucinous neoplasms of the pancreas: a midterm follow-up study. Clin Gastroenterol Hepatol. 2008; 6:807-814. [PubMed: 18304885]

23. Tang RS, Weinberg B, Dawson DW, et al. Evaluation of the guidelines for management of pancreatic branch-duct intraductal papillary mucinous neoplasm. Clin Gastroenterol Hepatol. 2008; 6:815-819. [PubMed: 18602036] 
24. Schmidt CM, White PB, Waters JA, et al. Intraductal papillary mucinous neoplasms: predictors of malignant and invasive pathology. Ann Surg. 2007; 246:644-654. [PubMed: 17893501]

25. Schnelldorfer T, Sarr MG, Nagorney DM, et al. Experience with 208 resections for intraductal papillary mucinous neoplasms of the pancreas. Arch Surg. 2008; 143:639-646. [PubMed: 18645105]

26. White R, D'Angelica M, Katabi N, et al. Fate of the remnant pancreas after resection of noninvasive intraductal papillary mucinous neoplasm. J Am Coll Surg. 2007; 204:987-995. [PubMed: 17481526]

27. Chari ST, Yadav D, Smyrk TC, et al. Study of recurrence after surgical resection of intraductal papillary mucinous neoplasm of the pancreas. Gastroenterology. 2002; 123:1500-1507. [PubMed: 12404225]

28. Waters JA, Schmidt CM, Pinchot JW, et al. CT vs MRCP: optimal classification of IPMN type and extent. J Gastrointest Surg. 2008; 12:101-109. [PubMed: 17917784] 

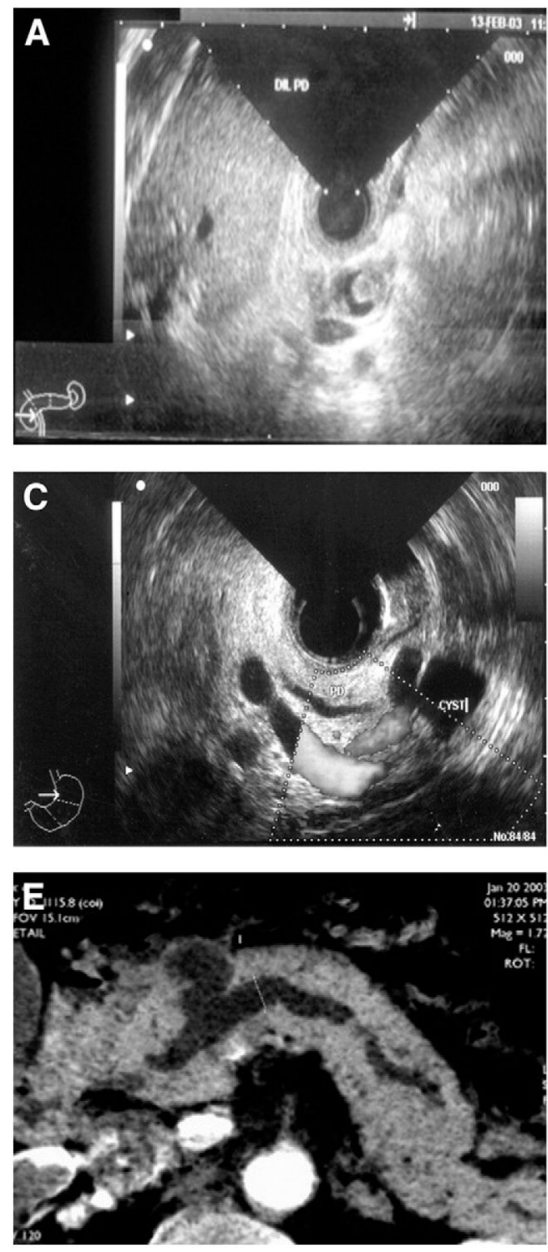

Figure 1.
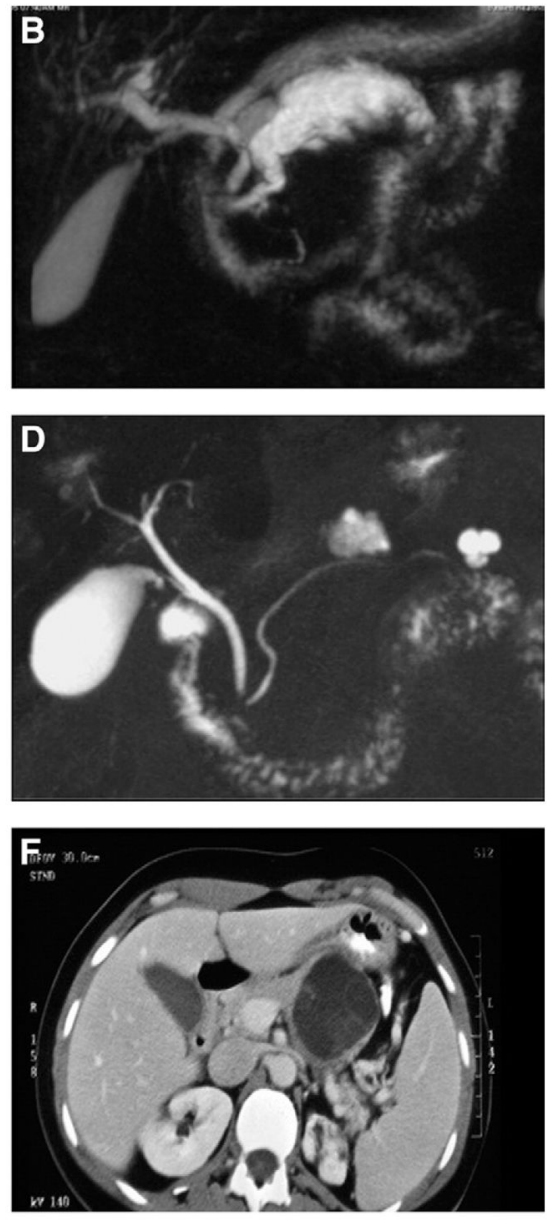

Examples of imaging of main-duct $(A, B)$, branch-duct $(C, D)$, combined IPMN $(E)$, and MCN $(F)$. $(A)$ Endoscopic ultrasound features with mural nodule in a dilated MPD. $(B)$ Main-duct IPMN at magnetic resonance cholangiopancreatography. (C) Branch-duct IPMN at endoscopic ultrasound. $(D)$ Multifocal branch-duct IPMN at magnetic resonance cholangiopancreatography. (E) Radiologic features of combined IPMN at computed tomography scan. $(F)$ Computed tomography features of an MCN. 
A

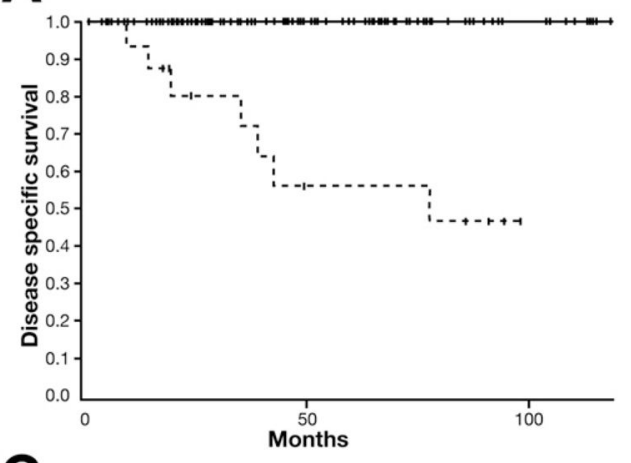

C

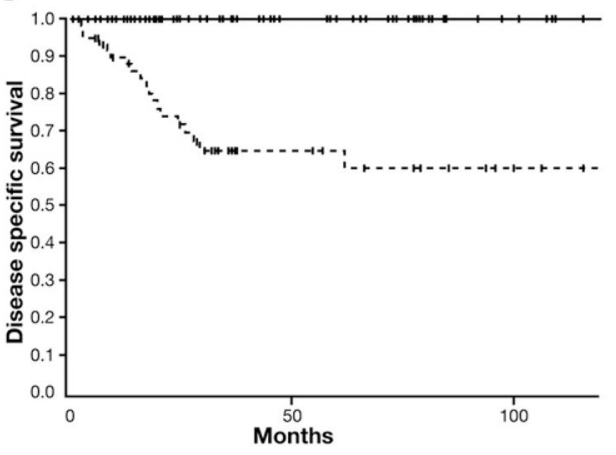

B
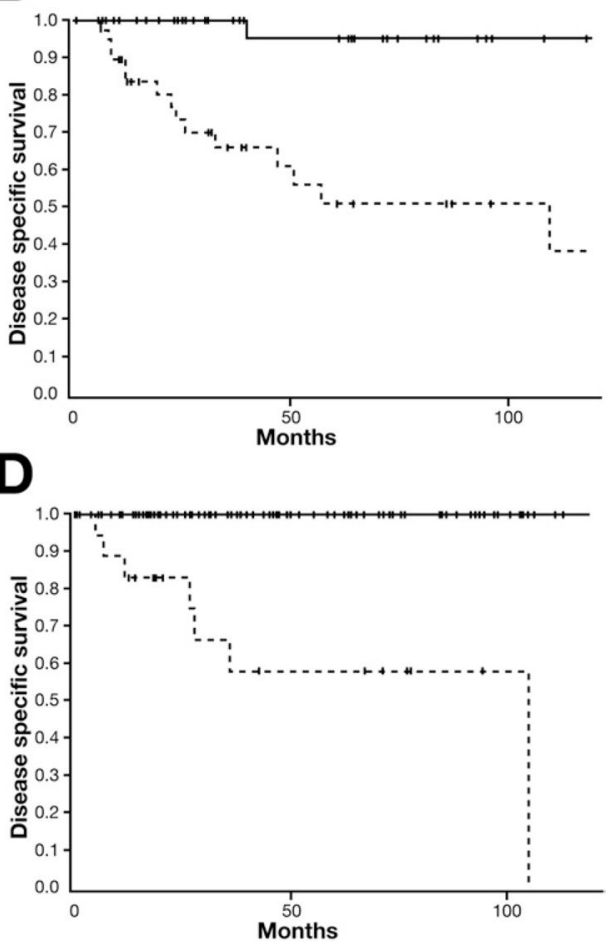

Figure 2.

Five-year disease-specific survival (DSS) comparing patients with noninvasive neoplasms including adenoma, borderline, and carcinoma in situ (black lines) and patients with invasive cancer (hatched lines) for different pancreatic MPNs. (A) DSS of $100 \%$ and $56 \%$ in noninvasive and invasive branch-duct IPMNs, respectively. (B) DSS of $95 \%$ and $51 \%$ in noninvasive and invasive main-duct IPMNs, respectively. (C) DSS of $100 \%$ and $64 \%$ in noninvasive and invasive combined IPMNs, respectively. $(D)$ DSS of $100 \%$ and $56 \%$ in noninvasive and invasive branch-duct IPMNs, respectively. 


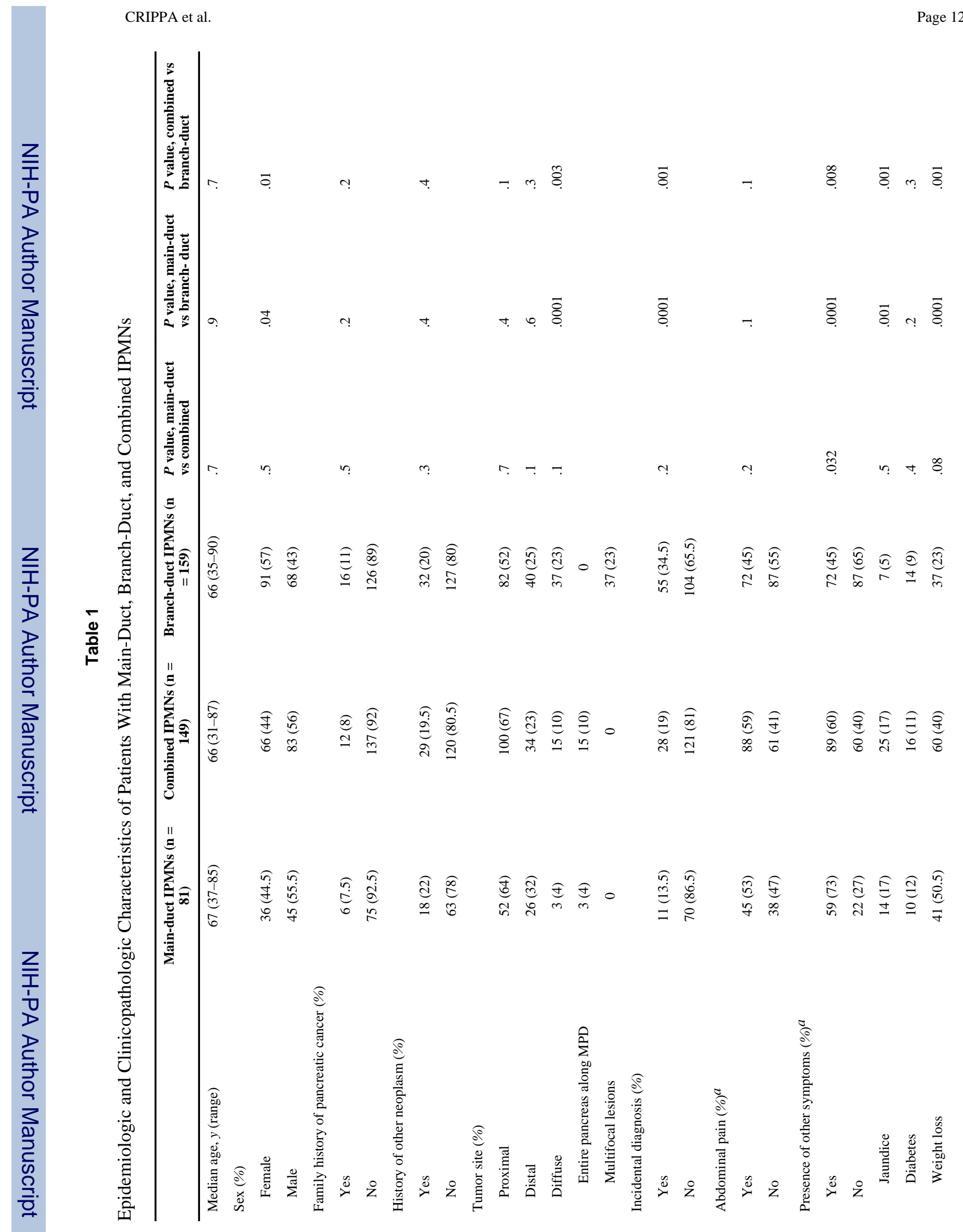

Clin Gastroenterol Hepatol. Author manuscript; available in PMC 2011 July 13. 


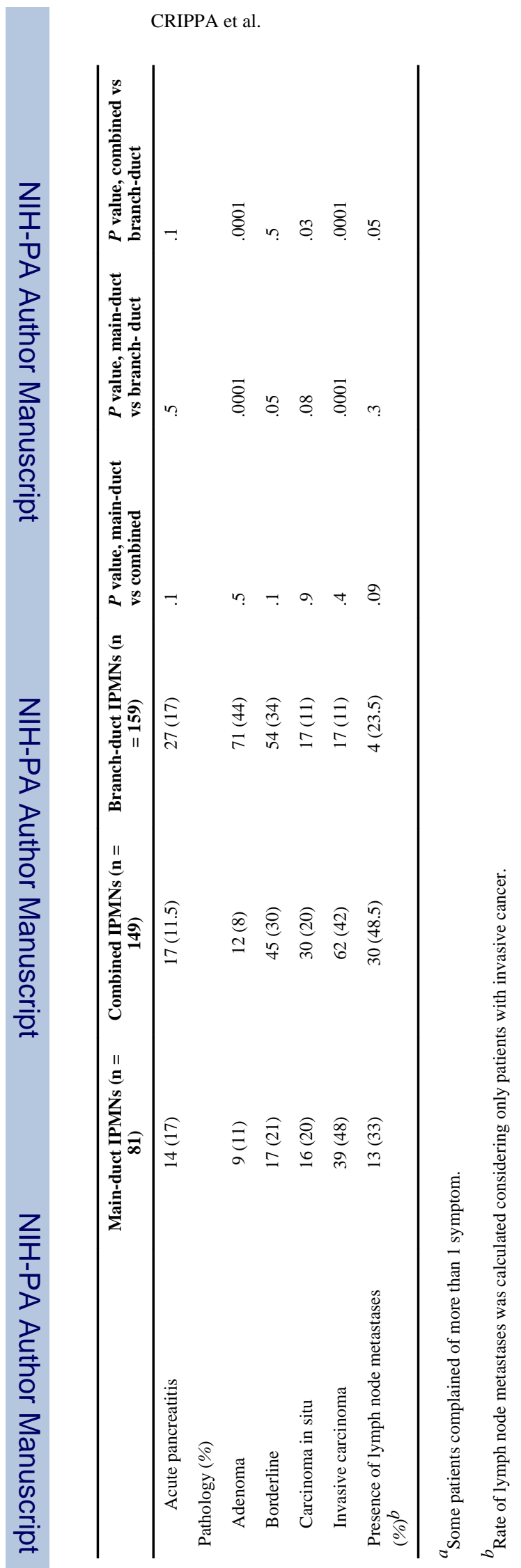

Page 13 
Table 2

Results of Multivariate Logistic Model Using Stepwise Selection Method for Patients With Main-Duct and Combined IPMNs Versus Those With Branch-Duct IPMNs

\begin{tabular}{llc}
\hline Variable & Hazard ratio $(\mathbf{9 5 \%}$ confidence interval) & $\boldsymbol{P}$ value \\
\hline Gender & $0.551(0.353-0.859)$ & .008 \\
Weight loss & $0.488(0.301-0.793)$ & .003 \\
Invasive neoplasm versus noninvasive & $0.167(0.093-0.298)$ & $<.0001$ \\
\hline
\end{tabular}


Table 3

Epidemiologic and Clinicopathologic Characteristics of Patients With MCNs Compared With Those With Branch-Duct IPMNs

\begin{tabular}{|c|c|c|c|}
\hline & MCNs $(n=168)$ & Branch-duct IPMNs $(n=159)$ & $P$ value \\
\hline Median age, $y$ (range) & $44.5(16-82)$ & $66(35-90)$ & .0001 \\
\hline \multicolumn{4}{|l|}{$\operatorname{Sex}(\%)$} \\
\hline Female & $160(95)$ & $91(57)$ & .0001 \\
\hline Male & $8(5)$ & $68(43)$ & \\
\hline \multicolumn{4}{|l|}{ Family history of pancreatic cancer (\%) } \\
\hline Yes & $6(3.5)$ & $16(11)$ & .01 \\
\hline No & $162(96.5)$ & $126(89)$ & \\
\hline \multicolumn{4}{|l|}{ History of other neoplasm (\%) } \\
\hline Yes & $15(9)$ & $32(20)$ & .006 \\
\hline No & $153(91)$ & $127(80)$ & \\
\hline \multicolumn{4}{|l|}{ Tumor site $(\%)$} \\
\hline Proximal & $5(3)$ & $82(52)$ & .0001 \\
\hline Distal & $163(97)$ & $40(25)$ & \\
\hline Multifocal lesions & 0 & $37(23)$ & \\
\hline \multicolumn{4}{|l|}{ Incidental diagnosis (\%) } \\
\hline Yes & $46(27.5)$ & $55(34.5)$ & .1 \\
\hline No & $122(72.5)$ & $104(65.5)$ & \\
\hline \multicolumn{4}{|l|}{ Abdominal pain (\%) ${ }^{a}$} \\
\hline Yes & $104(62)$ & $72(45)$ & .004 \\
\hline No & $64(38)$ & $87(55)$ & \\
\hline \multicolumn{4}{|l|}{ Presence of other symptoms (\%) ${ }^{a}$} \\
\hline Yes & $44(26 \%)$ & $72(45 \%)$ & .0001 \\
\hline No & $124(74 \%)$ & $87(65 \%)$ & \\
\hline Jaundice & $1(0.5)$ & $7(5)$ & .06 \\
\hline Diabetes & $9(5.5)$ & $14(9)$ & .3 \\
\hline Weight loss & $27(16)$ & $37(23)$ & .1 \\
\hline Acute pancreatitis & $9(5.5)$ & $27(17)$ & .001 \\
\hline \multicolumn{4}{|l|}{ Pathology (\%) } \\
\hline Adenoma & $122(73)$ & $71(44)$ & .0001 \\
\hline Borderline & $17(10)$ & $54(34)$ & .001 \\
\hline Carcinoma in situ & $10(6)$ & $17(11)$ & .2 \\
\hline Invasive carcinoma & $19(11)$ & $17(11)$ & .8 \\
\hline Median tumor size, mm (range) & $49(8-150)$ & $20(5-100)$ & .0001 \\
\hline Presence of lymph node metastases $(\%)^{b}$ & 0 & $4(23.5)$ & .08 \\
\hline
\end{tabular}


Table 4

Results of Multivariate Logistic Model by Using Stepwise Selection Method for Patients With MCNs Versus Those With Branch-Duct IPMNs

\begin{tabular}{llc}
\hline Variable & Hazard ratio $(\mathbf{9 5 \%}$ confidence interval) & $\boldsymbol{P}$ value \\
\hline Age & $1.130(1.088-1.172)$ & $<.0001$ \\
Gender & $3.168(1.114-9.013)$ & .03 \\
Acute pancreatitis & $10.75(2.813-41.120)$ & .0005 \\
Distal pancreas & $0.015(0.005-0.050)$ & $<.0001$ \\
\hline
\end{tabular}

